\title{
Series of Nanocrystalline NiCoAlFe(Cr, Cu, Mo, Ti) High-Entropy Alloys produced by Mechanical Alloying
}

\author{
Cynthia Deisy Gómez-Esparza ${ }^{a *}$, Francisco Baldenebro-López ${ }^{a, b}$, Leslie González-Rodelas ${ }^{c}$,
}

\author{
Jesús Baldenebro-López ${ }^{b}$,Roberto Martínez-Sánchez ${ }^{a}$
}

\author{
${ }^{a}$ Laboratorio Nacional de Nanotecnología, Centro de Investigación en Materiales Avanzados - CIMAV, \\ Miguel de Cervantes No. 120, 31136, Chihuahua, Chihuahua, México \\ ${ }^{b}$ Facultad de Ingeniería Mochis, Universidad Autónoma de Sinaloa, Prol. Angel Flores y Fuente de \\ Poseidón, S/N, 81223, Los Mochis, Sinaloa, México \\ ${ }^{c}$ Facultad de Ingeniería, Universidad Autónoma de Chihuahua, Circuito No. 1, Nuevo Campus \\ Universitario 2, Apdo. postal 1552, 31240, Chihuahua, Chihuahua, México
}

Received: November 4, 2015; Revised: May 26, 2016; Accepted: July 15, 2016

\begin{abstract}
The mechanical alloying technique was employed to produce series of high entropy alloys, combining in equiatomic percentage $\mathrm{Al}, \mathrm{Co}, \mathrm{Cr}, \mathrm{Cu}, \mathrm{Fe}, \mathrm{Mo}, \mathrm{Ni}$ and Ti. Milling times were $0,10,20$ and $30 \mathrm{~h}$, and experiments were performed in a high energy ball mill (SPEX-8000M) under argon atmosphere. The structural and microstructural changes due to mechanical alloying process were studied by X-ray diffraction and electron microscopy. Although there is the presence of pure elements with HCP crystalline structure, the XRD patterns of as-milled powders revealed the presence of a mixture of nanocrystalline solid solution with FCC and BCC structure phases. The hardness of the powder samples was evaluated by Vickers microhardness testing. The average microhardness values indicate that the alloy with the greatest hardness is the NiCoAlFeMoCr.
\end{abstract}

Keywords: High Entropy Alloys, Nanocrystalline Phases, Mechanical Alloying

\section{Introduction}

The high entropy alloys were developed by Yeh et al. in $2004^{1}$ and were label at this way due to their tendency to form solid solution phases instead of intermetallic compounds for the high mixing entropy even when they are composed of at least five principal elements ${ }^{2-5}$. The theory of traditional metallurgy, based on binary and ternary phase diagrams, suggests that multiple principal alloying elements can lead to the formation of various compounds with complex microstructures, as intermetallic compounds with poor mechanical properties due to embrittlement, in addition making the alloys difficult to process and complex to analyze. However, solid solutions of several elements tend to be more stable due to its high entropy of mixing. This indicates that the tendency to order and segregate will decrease with the high entropy of mixing. Therefore, it will be preferred the formation of solid solutions of multiple elements instead of intermetallic compounds ${ }^{1}$. The effect of high entropy is the preference of the systems by the formation of BCC and/or FCC solid solutions phases ${ }^{6,7}$. It is known that the phase stability directly affect the microstructure and properties ${ }^{8}$. One of the main parameters affecting the microstructural and mechanical properties of high entropy alloys is their chemical composition. It has been experimentally determined that each alloying element, with own crystalline structure, atomic radius and melting point has a direct effect on the physical and chemical properties of the alloy.

* e-mail: cynthia.gomez@cimav.edu.mx
High entropy alloys have emerged as a new type of advanced materials, and they have more attention among the scientific community ${ }^{9}$. Most of the reported studies on high entropy alloys involve a liquid processing route ${ }^{10,11}$. Mechanical alloying (MA) is a process in solid state that has been widely recognized as a processing route to produce solid solutions in nanoscale with unusual properties ${ }^{12}$ and is an alternate route for producing high entropy alloys ${ }^{13,14}$. Nanostructured high entropy alloys produced by MA have been reported with a high hardness, wear resistance, and superior resistance to temper softening ${ }^{15,16}$.

This investigation is focused on the synthesis of different equiatomic high entropy alloy by mechanical alloying, by varying the chemical composition from a quaternary NiCoAlFe system and adding an element at a time. The effect of alloying elements $\mathrm{Cr}, \mathrm{Cu}, \mathrm{Mo}$ and $\mathrm{Ti}$, and processing parameters on the structural evolution, microstructure and microhardness of alloys will be reported and discussed.

\section{Experimental}

Pure elemental powders of $\mathrm{Ni}, \mathrm{Co}, \mathrm{Al}, \mathrm{Fe}, \mathrm{Cu}, \mathrm{Cr}$, Mo and Ti with a purity level higher than $99 \%$ were used as raw materials. These powders were mixed to give equiatomic compositions to form 8 different high entropy alloys: NiCoAlFeCu, NiCoAlFeCuCr, NiCoAlFeCuCrTi, 
NiCoAlFeCr, NiCoAlFeTi, NiCoAlFeCrTi, NiCoAlFeMo and $\mathrm{NiCoAlFeMoCr}$. Hardened steel grinding media and grinding vessel were used for the MA process and methanol was used as a process control agent. The milling process was performed in a high energy shaker mill (SPEX-8000M), under argon atmosphere to avoid powders oxidation. Milling was conducted for 10,20 and $30 \mathrm{~h}$. The charge ratio was $\sim 5: 1$. The particle size distribution in milled products was measured by the laser diffraction and scattering method using a Mastersizer-2000 particle size analyzer. The as-milled powders were characterized by scanning electron microscopy (SEM) in a JEOL JSM-5800LV and a JEOL JSM-7401F, and transmission electron microscopy (TEM) using a JEOLJEM2200FS. The X-ray diffraction (XRD) tests were carried out in a Panalytical X'Pert PRO diffractometer with $\mathrm{Cu} \mathrm{K \alpha}$ radiation $(\lambda=1.5406 \AA)$. The step and acquisition time were $0.01^{\circ}$ and $260 \mathrm{~s}$, respectively. Micro-hardness of as-milled powders was performed under $50 \mathrm{~g}$ load with $10 \mathrm{~s}$ of dwell time using a LM 300AT Leco MicroHardness tester.

\section{Results and Discussion}

\subsection{Morphology and microstructure of powders.}

The powder shape is characterized by the surface contour of the individual particles, product of the manufacturing process to produce it. SEM micrographs of the pure elemental powders morphology are shown in Figure 1. Different particle size and morphology are observed. Spherical or rounded shapes, as those showed by $\mathrm{Cu}, \mathrm{Ni}$ and $\mathrm{Al}$ elemental powder, promote cold welding during mechanical alloying, the plastic characteristic of $\mathrm{Cu}$ and $\mathrm{Al}$ improve the cold compaction of powders. In the other hand, irregular and flake-shaped particles, observed in $\mathrm{Fe}, \mathrm{Cr}$ and $\mathrm{Ti}$, are related with higher hardness materials. It has been found that $\mathrm{Fe}, \mathrm{Cr}$ and $\mathrm{Ti}$ are easier to fracture during mechanical alloying but difficult the compaction process and therefore the sintering.

SEM micrographs of the microstructural and morphological evolution of milled powders as a function of the milling time of one system ( $\mathrm{NiCoAlFeCuCrTi}$ ), that is representative for all the studied alloys, are shown in Figure 2. Figures $2 a, 2 b$ and $2 c$ correspond to milling times of 10,20 and 30 $\mathrm{h}$, respectively. It can be appreciated the effect of milling on size and morphology of the powder particles, which acquire a homogeneous morphology (shape and roughness) after process typical AM in comparison to the mixture of elemental powders. During mechanical alloying process, the particles are cold-welded to form larger particles in the early stages of this process. At 10 and $20 \mathrm{~h}$ of milling the powders exhibit a wide particle size distribution. When the milling time is extended to $30 \mathrm{~h}$, the agglomerated particles tend to fracture and re-welded, this phenomenon leads to the homogenization and/or refinement of particle size. FE-
SEM images (Figures 2d, e, f) of the powders after milling revealed that the high energy of milling imposed on the powders led to the refinement of the lamellar microstructure as a function of the milling time.

\subsection{Particle size measurements.}

The particle size distributions of as-milled powders were obtained by laser diffraction. There are metallic systems that are very ductile, as the $\mathrm{NiCoAlFeCr}$ alloy which particle size increases with the milling time (Figure 3a). In the other hand, the $\mathrm{NiCoAlFeCuCr}, \mathrm{NiCoAlFeCuCr}, \mathrm{NiCoAlFeCrTi}$ and $\mathrm{NiCoAlFeTi}$ alloys increase their average particle size at 20 $\mathrm{h}$ of milling and decreases after $30 \mathrm{~h}$ (Figure $3 \mathrm{~b}$ ), while the NiCoAlFeCu, NiCoAlFeMo and NiCoAlFeMoCr systems exhibit particle size reduction at $20 \mathrm{hAM}$, then at $30 \mathrm{~h}$ of milling a slight increase is observed (Figure 3c). During the milling process, the balls impact the powder particles causing them to plastically deform and subsequently work hardening, which is then followed by fracture and re-welding of the particles. In some of the studied cases, the re-welding process is predominant over the fracturing process, and this is attributed to the ductility that remains in the mechanically alloyed powders, which may result into coarsening of the powder particles and slightly increase of particle size with the milling time.

\subsection{Structural evolution of as-milled powders}

Figure 4 shows the XRD patterns of two of the high entropy powder alloys after different milling times, which are representative for all the studied alloys. The characteristic Bragg's peaks of pure elemental powders were clearly detected for the mixed powders ( $0 \mathrm{~h}$ of milling). The intensity decreases drastically with the milling time. The diffraction peaks of pure elements disappear completely after $10 \mathrm{~h}$ of milling, emerging peaks allusive to the formation of a mixture of solid solutions FCC and/or BCC, with different $2 \theta$ values accordance with the adding elements. The peak broadening is related to the fine microstructure of the mechanical alloying powder, suggesting a transformation from microcrystalline starting powders (mixture, $0 \mathrm{~h}$ ) to nanocrystalline solid solutions milled powders $(10,20$ and $30 \mathrm{~h})$. The mechanical alloying process causes a decrease in crystalline size by increasing the fraction of grain boundaries and mechanical deformation; moreover, the deformation of the lattice increases with the milling time ${ }^{12}$.

Through TEM observations was possible to corroborate the nanocrystalline structure of milled powders observed in XRD patterns (Figure 5). The powder samples were then studied taking bright-field and dark-field images in combination with selected area electron diffraction (SAED) pattern to determine microstructural changes induced by the MA process. In Figure $5 \mathrm{~b}$ a dark-field image of the $\mathrm{NiCoAlFeCu}$ powder alloy provides high contrast for the grains whose diffracted electrons pass through the objective 

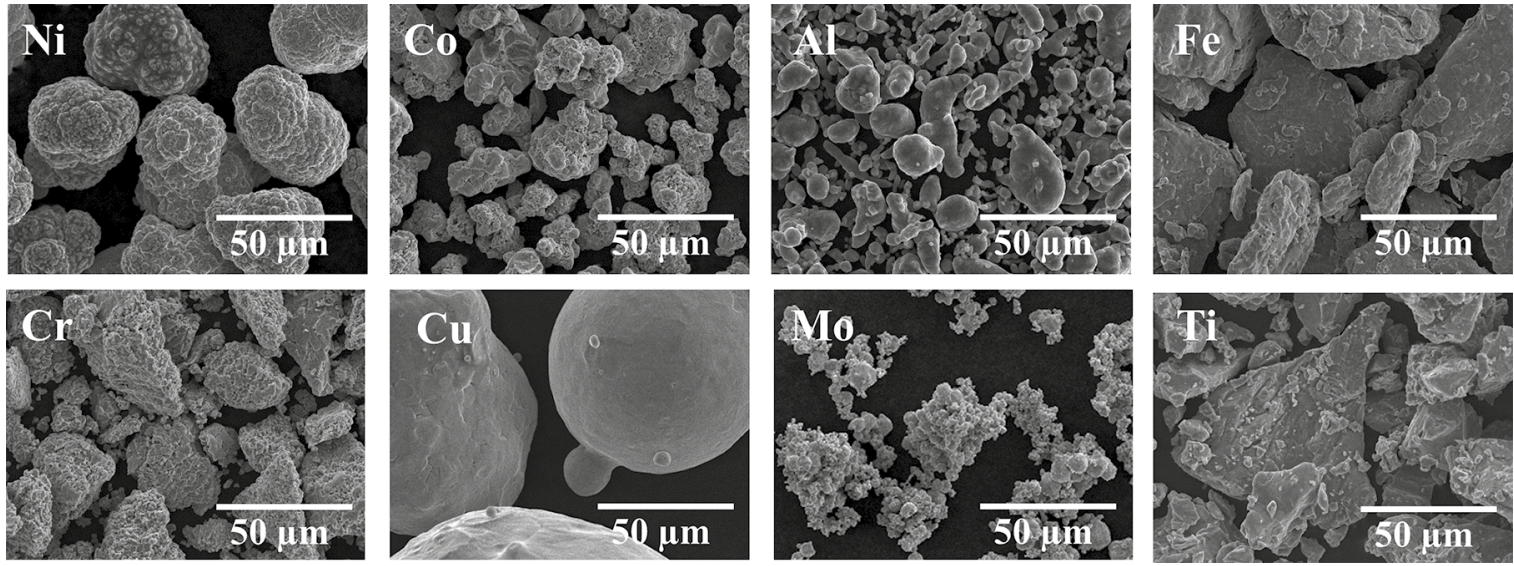

Figure 1: SEM micrographs of the elemental powders morphology.
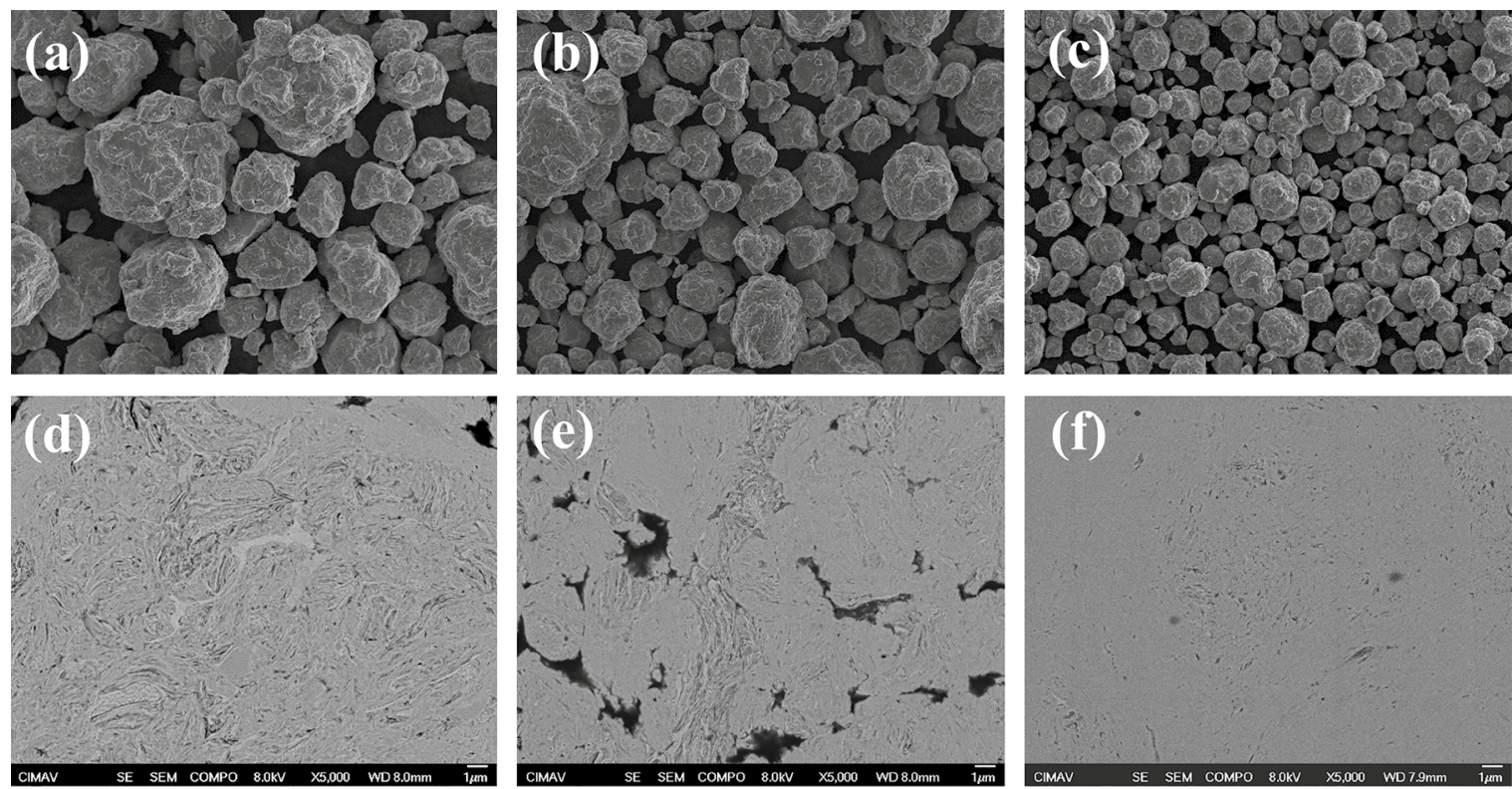

Figure 2: NiCoAlFeCuCrTi powders after 10, 20 and $30 \mathrm{~h}$ of milling respectively, showing their morphology in SEM micrographs (a, b and c), and lamellar microstructure in FE-SEM micrographs (d, e and f).
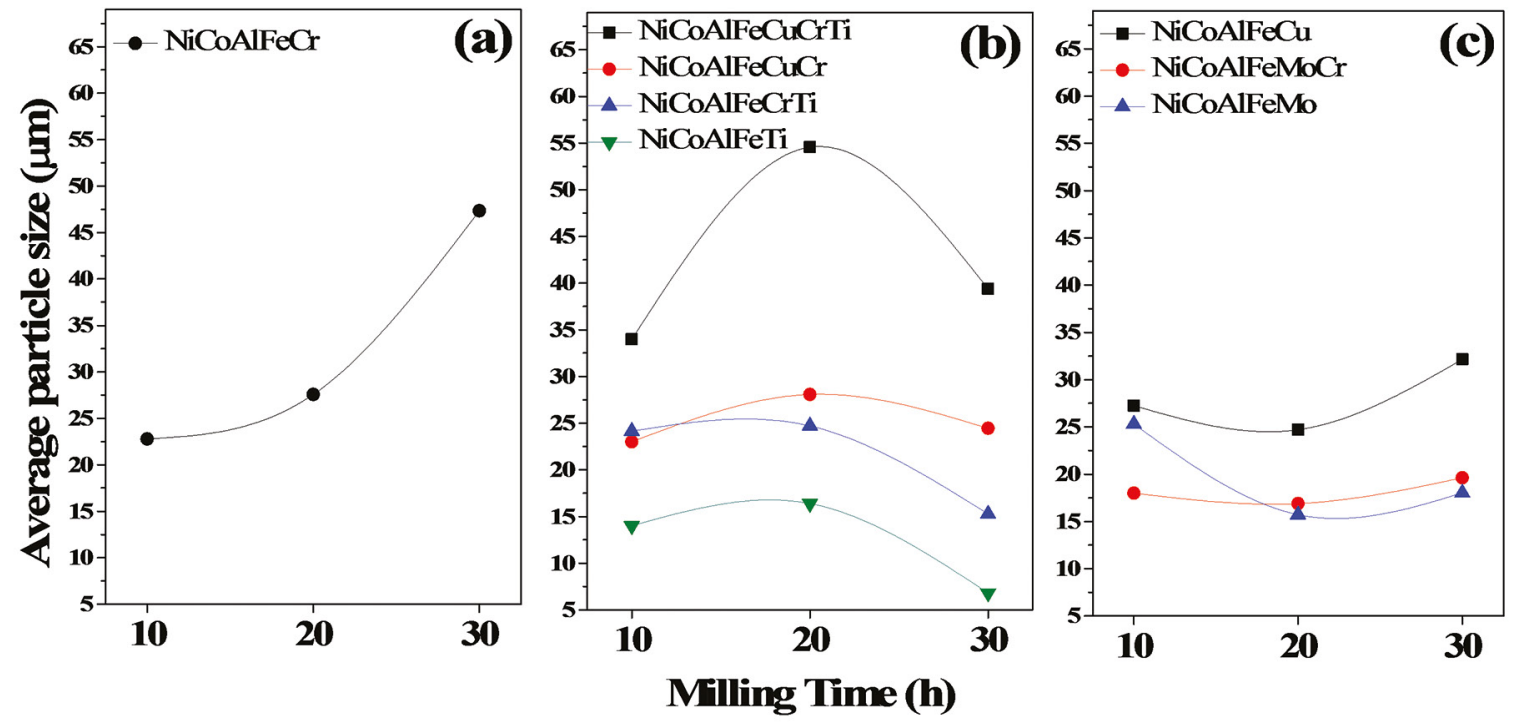

Figure 3: Average particle size of as-milled powders as a function of the milling time. 


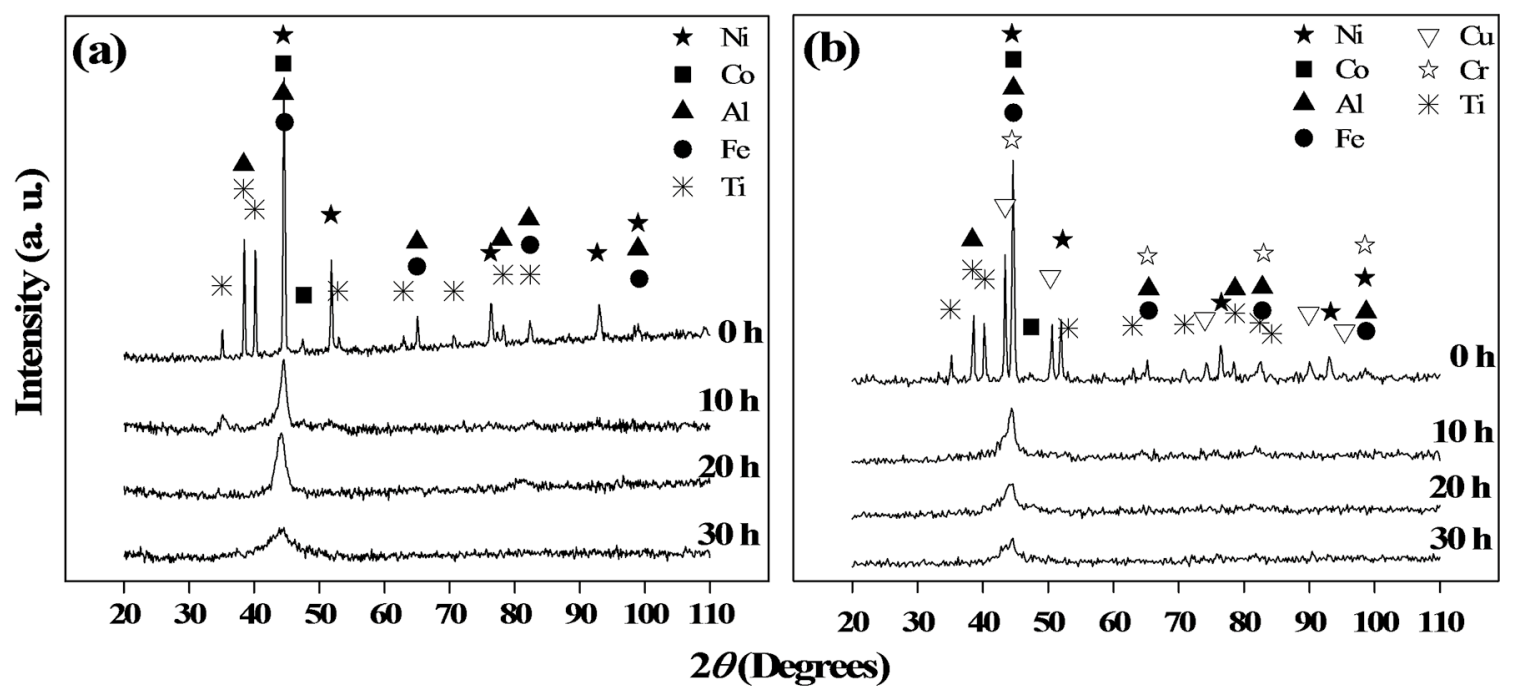

Figure 4. XRD patterns of the alloys: a) NiCoAlFeTi and b) NiCoAlFeCuCrTi, as a function of the milling time.

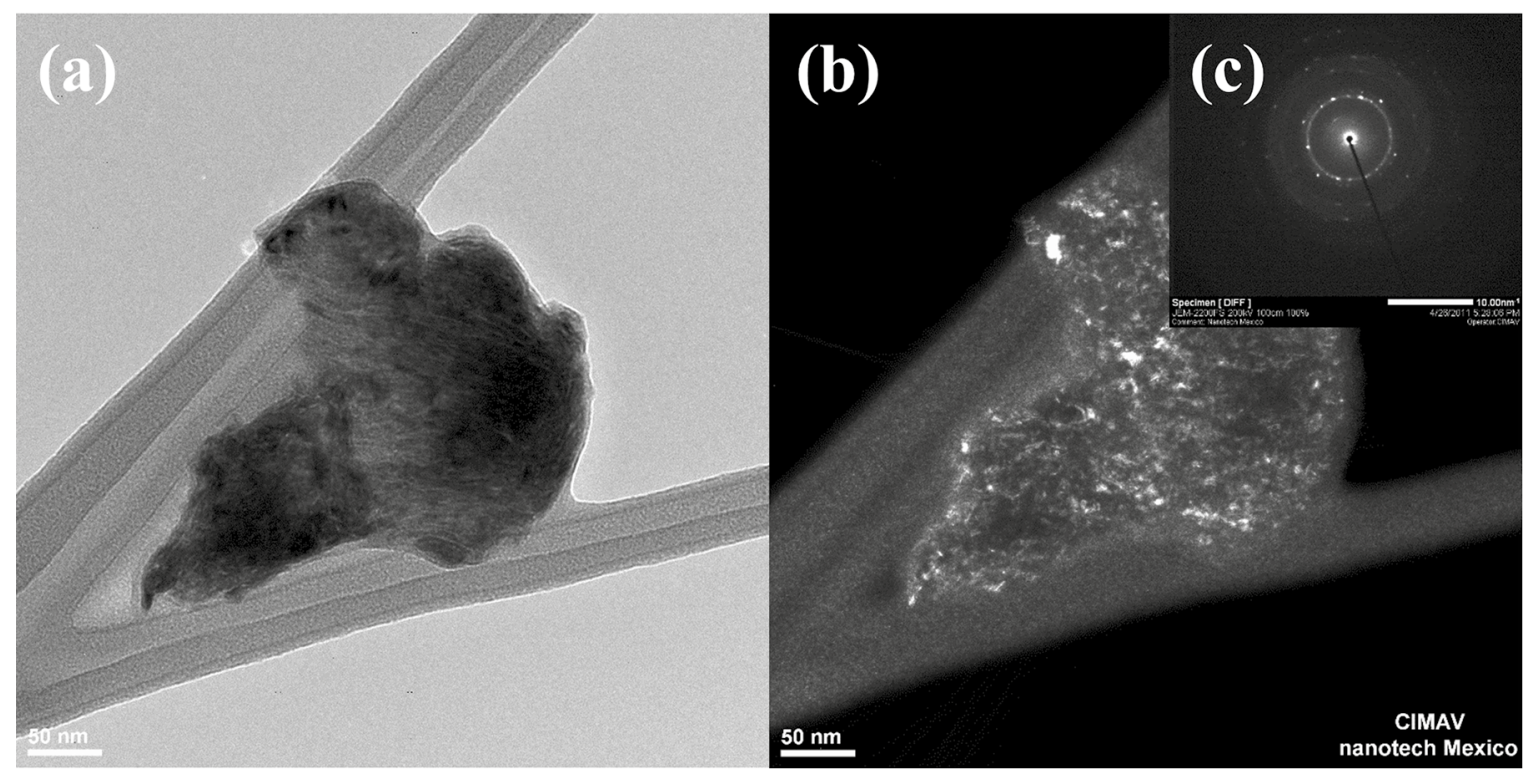

Figure 5: (a) Bright-field and (b) dark-field TEM images of NiCoAlFeCu alloy after $30 \mathrm{~h}$ milling as well as SAED pattern (c).

aperture, and shows a crystalline size in nano-scale (less than $20 \mathrm{~nm}$ ). In the other hand, fine polycrystalline signal (small points in fine rings) can be seen in the pattern of Figure $5 \mathrm{c}$. This suggests that the microstructure of powders alloys after milling is composed of a fine nanocrystalline structure. Even after the larger milling time $(30 \mathrm{~h})$ the crystalline size remain in nano-scale without reaching amorphization.

\subsection{Response of milled powders to sintering process}

Compacting followed by sintering is one of the processing routs to obtain bulk specimens from mechanically alloyed powders. One of the most important variables in the MA process is the milling time. This parameter affects the formation of new phases. The milling times used in this study $(10,20$ and $30 \mathrm{~h}$ ) does not affect significantly the formation of solid solution phases, however favors the homogeneity in chemical composition in milled powders. Hence, cold-pressing and sintering experiments were performed to determine the effect of milling time on porosity of bulk samples (a temperature of $1200{ }^{\circ} \mathrm{C}$ for $3 \mathrm{~h}$ in vacuum was used for all the alloys). SEM observations were made of polished cross sections of sintered samples (Figure 6) giving evidence about that pores density increases with the milling time. Mechanically alloyed powders exhibit high dislocation density ${ }^{12,17}$ that affects the response during compaction and sintering promoting an increase in porosity and hence poor mechanical properties 
in bulk samples. According to these results, it is suggested that a suitable milling time to obtain bulk specimens for the studied alloys is $10 \mathrm{~h}$.

\subsection{Influence of chemical composition, structural behavior and microhardness of powders milled during $10 \mathrm{~h}$}

Figure 7 presents the particle size distribution curves of milled powders for $10 \mathrm{~h}$ as a function of chemical composition. The median particle size of $\mathrm{NiCoAlFeCu}$ alloy is $\mathrm{d}_{0.5}=27.2 \mu \mathrm{m}$. With chromium addition the $\mathrm{d}_{0.5}$ value decreases to $23.0 \mu \mathrm{m}$, exhibiting a bimodal distribution with agglomerated particles in the range of $\sim 1500 \mu \mathrm{m}$.
$\mathrm{Ti}$ addition promotes the increase of particle size in $50 \%$ respect to the $\mathrm{NiCoAlFeCuCr}$ alloy $\left(\mathrm{d}_{0.5}=33.9 \mu \mathrm{m}\right)$. The NiCoAlFeCr, NiCoAlFeTi and NiCoAlFeTiCr alloys have $\mathrm{d}_{0.5}$ values of $22.77,14.48$ and $24.24 \mu \mathrm{m}$, respectively. The powder alloys with no content of $\mathrm{Cu}$ present a slightly reduction in particle size. The $\mathrm{NiCoAlFeCr}$ and $\mathrm{NiCoAlFeCrTi}$ alloys present distributions that are skewed to the right in the range of $150 \mu \mathrm{m}$, while NiCoAlFeTi alloy exhibit a bimodal distribution, with agglomerated particles in the range of $450 \mu \mathrm{m}$. The NiCoAlFeMo $\left(\mathrm{d}_{0.5}=\right.$ $25.31 \mu \mathrm{m})$ and $\mathrm{NiCoAlFeMoCr}\left(\mathrm{d}_{0.5}=18.15 \mu \mathrm{m}\right)$ present bimodal distributions. Mo and $\mathrm{Cr}$ are materials that exhibit high hardness as pure elements. Both of them promote the reduction of particle size.
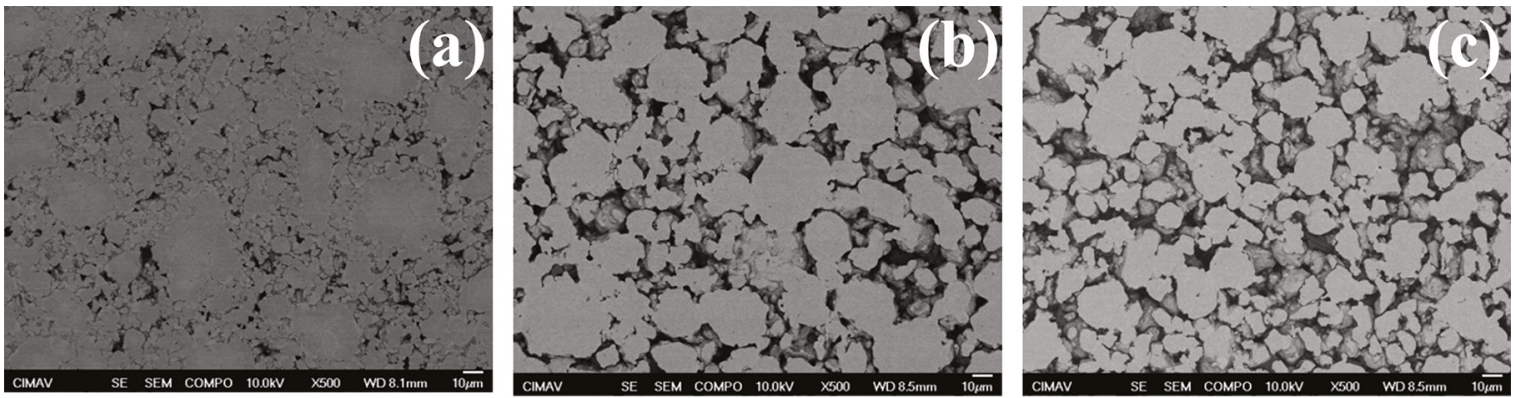

Figure 6: SEM images of sintered NiCoAlFeCuCr alloys as a function of the milling time: a) 10, b) 20 and c) $30 \mathrm{~h}$.
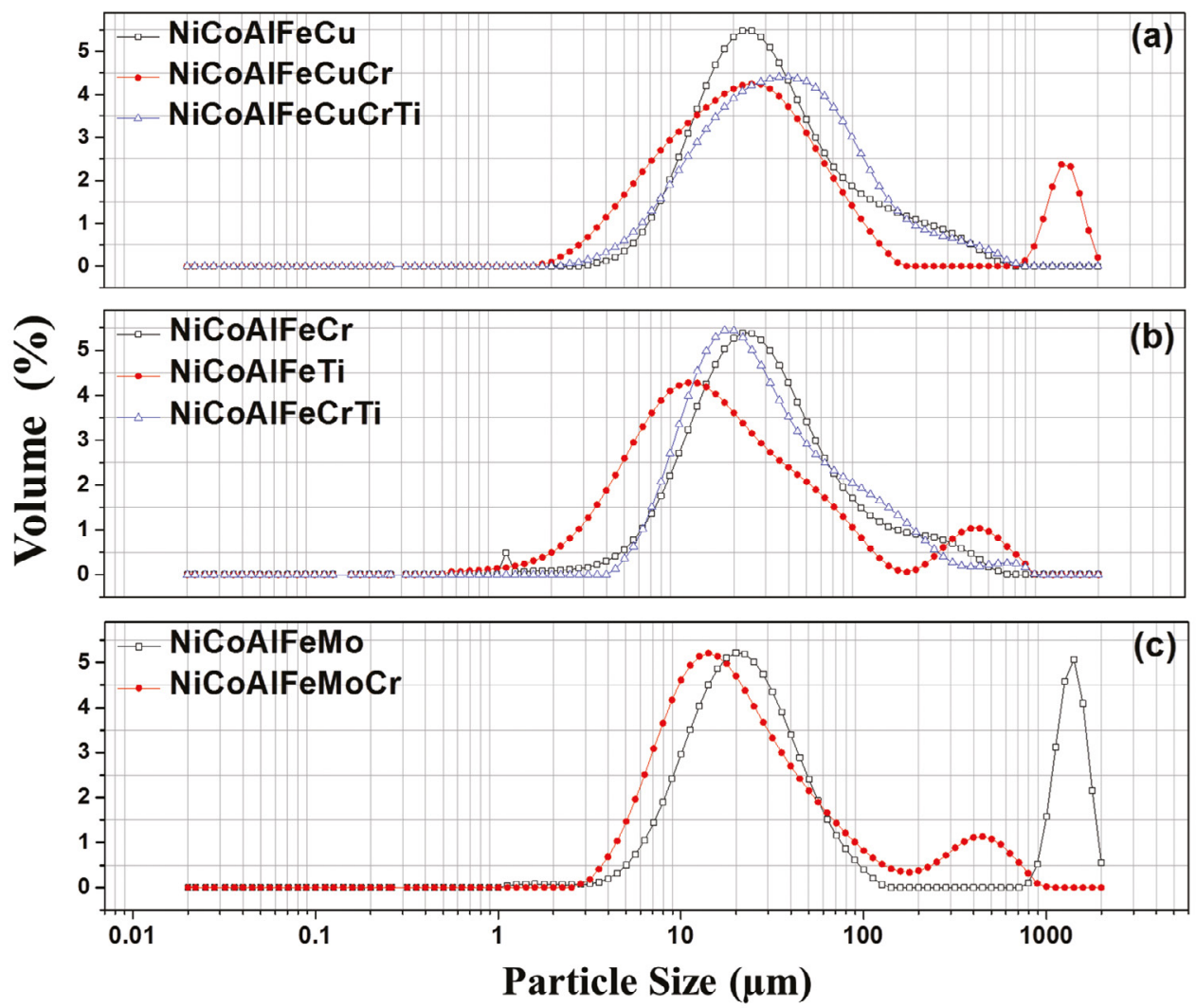

Figure 7: Particle size distribution curves of powders milled for $10 \mathrm{~h}$, as a function of chemical composition. 
The XRD patterns of milled powders for $10 \mathrm{~h}$ are shown in Figure 8. The NiCoAlFeCu, NiCoAlFeCuCr, NiCoAlFeCuCrTi, $\mathrm{NiCoAlFeCr,} \mathrm{NiCoAlFeTi} \mathrm{and} \mathrm{NiCoAlFeMo} \mathrm{alloys} \mathrm{present}$ a mixture of FCC + BCC solid solution phases, while the $\mathrm{NiCoAlFeTiCr}$ and NiCoAlFeMoCr alloys only exhibit the formation of BCC-type phases. In the $\mathrm{NiCoAlFeCu}$ and $\mathrm{NiCoAlFeCuCr}$ alloys a FCC-type phase is predominant, while in the rest of the alloys a BCC-type phase prevails.

Measurements of the full-width at half-maximum intensity (FWHM) were done to determine the crystallite size of milled powders using the Scherrer's formula. Instrumental correction has been possible using a standardized silicon sample. The crystalline size indicates that powders high entropy powder alloys possess nanocrystalline structure. The crystalline size, microdeformation, lattice parameter as well as microhardness values are displayed in Table 1. However, the overlap of adjacent crystalline peaks did not allow the measurement of all phases listed in Table 1.

According to the lattice parameter, all the alloys possess a Fe-type BCC solid solution which lattice parameter is very close to that of pure Fe $(0.286 \mathrm{~nm})$, except the NiCoAlFeMo, which has a Mo-type BCC phase $\left(\mathrm{a}_{\text {pure Mo }}=0.315 \mathrm{~nm}\right)$, while the $\mathrm{NiCoAlFeMoCr}$ alloy possesses both, a Fe-type and a Mo-type BCC phases. Respect to FCC phases, the alloys containing $\mathrm{Cu}$ present the formation of $\mathrm{Cu}$-type $\mathrm{FCC}$ phases $\mathrm{a}_{\text {pure } \mathrm{Cu}}=$
$0.361 \mathrm{~nm}$ ), while the NiCoAlFeCr and NiCoAlFeMo alloys have peaks corresponding to a Ni-type FCC solid solution $\left(a_{\text {pure } \mathrm{Ni}}=0.352 \mathrm{~nm}\right)$. It has been reported the formation of a BCC phase with the addition of aluminum ${ }^{18,19}$, however, the NiCoAlFeTi is the only alloy that exhibit the formation of an Al-type FCC phase $\left(a_{\text {pure Al }}=0.405 \mathrm{~nm}\right)$; in this case the aluminum acts a FCC phase former.

The reported values of microhardness test are the average of 50 measurements. These results indicate that the hardest powder alloy is the NiCoAlFeMoCr followed by the NiCoAlFeCrTi and NiCoAlFeMo alloys. This suggests that additions of $\mathrm{Mo}$ and $\mathrm{Cr}$ in mechanically alloyed powders benefit the increase of hardness.

\section{Conclusions}

Series of $\mathrm{NiCoAlFe}(\mathrm{Cr}, \mathrm{Cu}, \mathrm{Mo}, \mathrm{Ti})$ high entropy alloys were successful synthesized by mechanical alloying inducing the formation of nanocrystalline BCC and/or FCC phases. The chemical composition of alloys affects significantly the morphological, microstructural and structural characteristics of the alloys. $\mathrm{Ni}$ and $\mathrm{Cu}$ elements act as FCC formers, while $\mathrm{Fe}, \mathrm{Cr}$ and Mo promote the formation of $\mathrm{BCC}$ solid solution phases. Even when the $\mathrm{Al}$ has been reported as a $\mathrm{BCC}$ phase

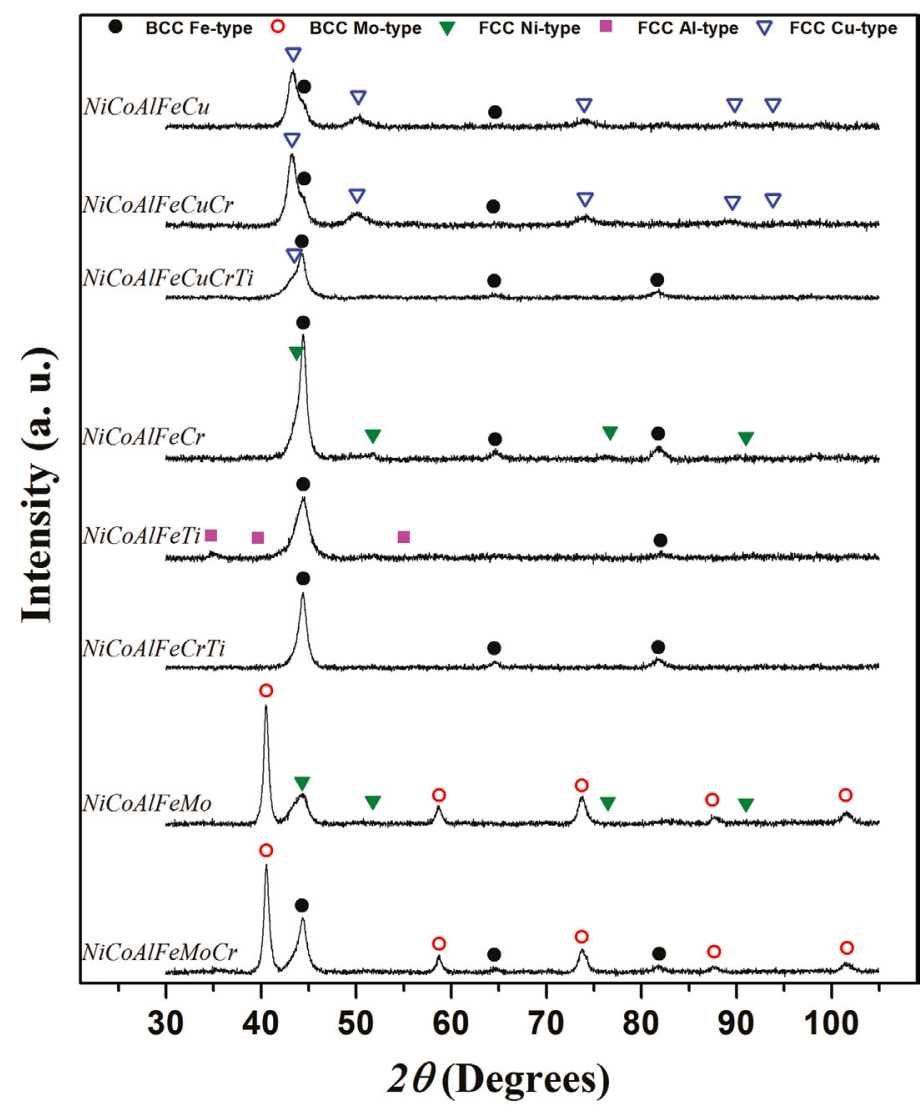

Figure 8: XRD patterns of powders after $10 \mathrm{~h}$ of milling showing the structural evolution as a function of the chemical composition. 
Table 1: Structural characteristics and microhardness of high entropy alloy powders milled for $10 \mathrm{~h}$.

\begin{tabular}{|c|c|c|c|c|c|}
\hline Alloy & Phase & Lattice parameter (nm) & Crystalline size (nm) & Micro-deformation $\left(\times 10^{-4}\right)$ & Hardness (HV) \\
\hline \multirow[t]{2}{*}{$\mathrm{NiCoAlFeCu}$} & BCC Fe-type & 0.288 & -- & -- & 583 \\
\hline & FCC Cu-type & 0.362 & 7.1 & 1.431 & \\
\hline \multirow[t]{2}{*}{$\mathrm{NiCoAlFeCuCr}$} & BCC Fe-type & 0.288 & - - & - & 482 \\
\hline & FCC Cu-type & 0.363 & 7.0 & 1.441 & \\
\hline \multirow[t]{2}{*}{ NiCoAlFeCuCrTi } & BCC Fe-type & 0.288 & 6.8 & 1.455 & 584 \\
\hline & FCC Cu-type & 0.367 & - & - & \\
\hline \multirow[t]{2}{*}{$\mathrm{NiCoAlFeCr}$} & BCC Fe-type & 0.287 & 10.9 & 0.944 & 596 \\
\hline & FCC Ni-type & 0.354 & - & -- & \\
\hline \multirow[t]{2}{*}{ NiCoAlFeTi } & BCC Fe-type & 0.288 & 5.6 & 1.738 & 583 \\
\hline & FCC Al-type & 0.407 & 10.3 & 1.264 & \\
\hline $\mathrm{NiCoAlFeCrTi}$ & BCC Fe-type & 0.288 & 10.0 & 1.023 & 692 \\
\hline \multirow[t]{2}{*}{ NiCoAlFeMo } & BCC Mo-type & 0.314 & 17.6 & 0.675 & 601 \\
\hline & FCC Ni-type & 0.353 & 4.9 & 1.990 & \\
\hline \multirow[t]{2}{*}{$\mathrm{NiCoAlFeMoCr}$} & BCC Mo-type & 0.314 & 16.5 & 0.715 & 766 \\
\hline & BCC Fe-type & 0.288 & 8.3 & 1.205 & \\
\hline
\end{tabular}

- - Values could not be measured.

former, in the NiCoAlFeTi powder alloy, the formation of an Al-type FCC phase is promoted. In the other hand, the alloys containing Mo exhibit the higher values of microhardness.

\section{Acknowledgments}

The authors gratefully acknowledge to W. AntunezFlores, K. Campos-Venegas, E. Torres-Moye and C.E. Ornelas-Gutiérrez for their technical assistance.

\section{References}

1. Yeh JW, Chen SK, Lin SJ, Gan JY, Chin TS, Shun TT, et al. Nanostructured High-Entropy Alloys with Multiple Principal Elements: Novel Alloy Design Concepts and Outcomes. Advanced Engineering Materials. 2004;6(5):299-303.

2. Singh S, Wanderka N, Murty BS, Glatzel U, Banhart J. Decomposition in multi-component $\mathrm{AlCoCrCuFeNi}$ high-entropy alloy. Acta Materialia. 2011;59(1):182-190.

3. Li BS, Wang YP, Ren MX, Yang C, Fu HZ. Effects of Mn, Ti and $\mathrm{V}$ on the microstructure and properties of $\mathrm{AlCrFeCoNiCu}$ high entropy alloy. Materials Science and Engineering: A. 2008;498(1-2):482-486.

4. Zhang KB, Fu ZY, Zhang JY, Wang WM, Lee SW, Niihara K. Characterization of nanocrystalline CoCrFeNiTiAl high-entropy solid solution processed by mechanical alloying. Journal of Alloys and Compounds. 2010;495(1):33-38.

5. Zhang KB, Fu ZY, Zhang JY, Wang WM, Wang H, Wang YC, et al. Microstructure and mechanical properties of $\mathrm{CoCrFeNiTiAl}$ high-entropy alloys. Materials Science and Engineering: $A$. 2009;508(1-2):214-219.
6. Li A, Zhang X. Thermodynamic analysis of the simple microstructure of $\mathrm{AlCrFeNiCu}$ high-entropy alloy with multi-principal elements. Acta Metallurgica Sinica (English Letters). 2009;22(3):219-224.

7. Li C, Li JC, Zhao M, Jiang Q. Effect of alloying elements on microstructure and properties of multiprincipal elements high-entropy alloys. Journal of Alloys and Compounds. 2009;475(1-2):752-757.

8. Yeh JW, Chen YL, Lin SJ, Chen SK. High-Entropy Alloys - ANew Era of Exploitation. Materials Science Forum. 2007;560:1-9.

9. Tsai MH, Yeh JW. High-Entropy Alloys: A Critical Review. Materials Research Letters. 2014;2(3):107-123.

10. Jiang L, Lu Y, Wu W, Cao Z, Li T. Microstructure and Mechanical Properties of a $\mathrm{CoFeNi} \mathrm{V}_{0.5} \mathrm{Nb}_{0.75}$ Eutectic High Entropy Alloy in As-cast and Heat-treated Conditions. Journal of Materials Science \& Technology. 2016;32(3):245-250.

11. Yu Y, Wang J, Li J, Kou H, Liu W. Characterization of BCC phases in $\mathrm{AlCoCrFeNiTi}_{x}$ high entropy alloys. Materials Letters. 2015;138:78-80.

12. Suryanarayana C. Mechanical alloying and milling. Progress in Materials Science. 2001;46(1-2):1-184.

13. Chen Z, Chen W, Wu B, Cao X, Liu L, Fu Z. Effects of Co and Ti on microstructure and mechanical behavior of $\mathrm{Al}_{0.75} \mathrm{FeNiCrCo}$ high entropy alloy prepared by mechanical alloying and spark plasma sintering. Materials Science and Engineering: A 2015;648:217-224.

14. Fu Z, Chen W, Wen H, Chen Z, Lavernia EJ. Effects of Co and sintering method on microstructure and mechanical behavior of a high-entropy $\mathrm{Al}_{06} \mathrm{NiFeCrCo}$ alloy prepared by powder metallurgy. Journal of Alloys and Compounds. 2015;646:175-182.

15. Sajith babu C, Sivaprasad K, Muthupandi V, Szpunar JA. Characterization of Nanocrystalline AlCoCrCuNiFeZn High Entropy Alloy Produced by Mechanical Alloying. Procedia Materials Science. 2014;5:1020-1026. 
16. Qiu XW. Microstructure and properties of $\mathrm{AlCrFeNiCoCu}$ high entropy alloy prepared by powder metallurgy. Journal of Alloys and Compounds. 2013;555:246-249.

17. Upadhyaya GS. Powder Metallurgy Technology. Cambridge: Cambridge International Science Publishing; 2002.
18. Wu JM, Lin SJ, Yeh JW, Chen SK, Huang YS, Chen HC. Adhesive wear behavior of $\mathrm{Al}_{x} \mathrm{CoCrCuFeNi}$ high-entropy alloys as a function of aluminum content. Wear. 2006;261(5-6):513-519.

19. Tong CJ, Chen MR, Yeh JW, Lin SJ, Chen SK, Shun TT, et al. Mechanical performance of the $\mathrm{Al}_{x} \mathrm{CoCrCuFeNi}$ high-entropy alloy system with multiprincipal elements. Metallurgical and Materials Transactions A. 2005;36(5):1263-1271. 